\title{
Effects of breastfeeding on respiratory symptoms in infancy
}

Olga Gorlanova $^{\mathrm{a}^{*}}$, MD, Simone Thalmann ${ }^{\mathrm{a}^{*}}$, Elena Proietti ${ }^{\mathrm{a}, \mathrm{b}}, \mathrm{MD}$, Georgette Stern ${ }^{\mathrm{b}}, \mathrm{PhD}$, Philipp Latzin ${ }^{\mathrm{a}, \mathrm{b}}$, MD, PhD, Claudia Kühni ${ }^{\mathrm{c}}, \mathrm{MD}, \mathrm{PhD}$, Martin Röösli ${ }^{\mathrm{d}}, \mathrm{PhD}$, Urs Frey ${ }^{\mathrm{a}}, \mathrm{MD}$, $\mathrm{PhD}$

Affiliations: 'University Children's Hospital (UKBB), University of Basel, Basel,

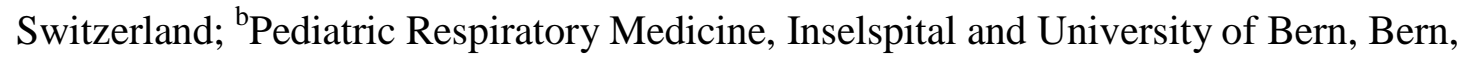

Switzerland; ' Institute of Social and Preventive Medicine (ISPM), University of Bern, Bern,

Switzerland; ${ }^{\mathrm{d}}$ Swiss Tropical and Public Health Institute, University of Basel, Basel,

Switzerland

\section{Corresponding author and address for reprint requests:}

Urs Frey, MD PhD

University Children's Hospital (UKBB)

Spitalstrasse 33

4056 Basel, Switzerland

Phone: +41617041900

Fax : $\quad+41617041253$

Email: urs.frey@ukbb.ch

*Contributed equally

Supported by the Swiss National Science Foundation (324730_144280). The authors declare no conflicts of interest.

Portions of the study were presented as a poster at the European Respiratory Society conference, September 7-11, 2013, Barcelona, Spain. 


\section{Abstract \\ Objective}

To assess the impact of potential risk factors on the development of respiratory symptoms and their specific modification by breastfeeding in infants in the first year of life

\section{Study design}

We prospectively studied 436 healthy term infants from the Bern-Basel Infant Lung Development (BILD) cohort. The breastfeeding status, and incidence and severity of respiratory symptoms (score) were assessed weekly by telephone interview during the first year of life. Risk factors (e.g. pre- and postnatal smoking exposure, mode of delivery, gestational age, maternal atopy, and number of older siblings) were obtained using standardized questionnaires. Weekly measurements of particulate matter $<10 \mu \mathrm{g}\left(\mathrm{PM}_{10}\right)$ were provided by local monitoring stations. The associations were investigated using generalized additive mixed model with quasi Poisson distribution.

\section{Results}

Breastfeeding reduced the incidence and severity of the respiratory symptom score mainly in the first 27 weeks of life (risk ratio $=0.70 ; 95 \%$ confidence interval, $0.55-0.88$ ). We found a protective effect of breastfeeding in girls, but not in boys. During the first 27 weeks of life, breastfeeding attenuated the effects of maternal smoking during pregnancy, gestational age, and cesarean delivery on respiratory symptoms. There was no evidence for an interaction between breastfeeding and maternal atopy, number of older siblings, child care attendance, or $\mathrm{PM}_{10}$

\section{Conclusion}

This study shows the risk-specific effect of breastfeeding on respiratory symptoms in early life using the comprehensive time-series approach. 


\section{Abbreviations:}

BILD Cohort

GAMM

RR

CI

NABEL

$\mathrm{PM}_{10}$

$\mathrm{NO}_{2}$
Bern-Basel Infant Lung Development Cohort

generalized additive mixed model;

risk ratio

confidence interval

Swiss National Air Pollution Network;

particulate matter smaller than about 10 micrometers;

nitrogen dioxide 
Acute respiratory infection is a major cause of morbidity and hospitalization among young children worldwide. Several hereditary risk factors ${ }^{1,2}$, perinatal factors, ${ }^{3-5}$ factors associated with immune development (maternal atopy, asthma), ${ }^{6,7}$ as well as environmental factors are known to increase the risk of lower respiratory tract disease in infants. Pre- and postnatal maternal smoking, and environmental exposure to particulate matter $<10 \mu \mathrm{g}\left(\mathrm{PM}_{10}\right)$ and nitrogen dioxide $\left(\mathrm{NO}_{2}\right)$, are correlated with more respiratory symptoms in the first year of life. $1,8,9$

Breastfeeding is generally accepted to be protective against respiratory symptoms in early life. ${ }^{2,10-14}$ Furthermore, growing knowledge indicates that breastfeeding may differentially affect susceptible subgroups. A number of studies found evidence of a protective effect of breastfeeding against respiratory infection, particularly in the first 4-6 months of life. ${ }^{2,10,12-15}$ Other studies have reported a protective effect of breastfeeding only in girls ${ }^{16-18}$ and in the first born child. ${ }^{19}$ Some studies have suggested that breastfeeding reduced the adverse effects of smoking ${ }^{20-22}$ and air pollution ${ }^{20}$ exposure on respiratory morbidity. However, most studies are cross-sectional ${ }^{16,17,20,22,23}$ and, therefore, prone to bias, due to the close concordance of lifestyle factors and socio-economic status, which relate to smoking rates, inhabiting polluted areas, and breastfeeding. In developed countries, breastfeeding mothers tend to have a higher education status and smoke less. ${ }^{24,}{ }^{25}$ Moreover, it is unknown whether breastfeeding may favourably influence the association of respiratory symptoms with the mode of delivery and gestational age.

We hypothesize that the protective effect of breastfeeding might be specifically modified dependent on the nature of the exposure to hereditary, perinatal, or environmental risk factors. In order to test our hypothesis, we aim to investigate whether breastfeeding can modify the 
relationship of respiratory symptoms with age, hereditary risk factors (sex, maternal atopy, and maternal asthma), perinatal factors (gestational age, cesarean delivery) and environmental factors $\left(\mathrm{PM}_{10}\right.$, and prenatal and postnatal tobacco exposure, number of older siblings, and child care attendance) within the prospective Bern-Basel Infant Lung Development (BILD) birth cohort study from Switzerland. We look at these effects in healthy term infants, using a statistical time series approach that accounts for breastfeeding status and environmental air pollutant exposure on a week-by-week basis. The novelty of our approach is that we made comparisons within the same child on a weekly basis, so the effect of common confounders was minimized. 


\section{Methods}

Data was taken from the ongoing prospective Basel-Bern Infant Lung Development (BILD) birth cohort study, ${ }^{26}$ and included 436 unselected healthy newborns born in Bern, Switzerland between April 1999 and November 2013, with complete information about breastfeeding status. Recruitment, and inclusion and exclusion criteria are described elsewhere, ${ }^{1,26}$ Written consent was obtained from all parents, and the Ethics Committees of the Regions of Basel and Bern approved the study.

\section{$\underline{\text { Outcome }}$}

As previously described ${ }^{1,8,26,27}$, respiratory symptoms (cough, wheezing, and difficulty breathing) were collected in weekly telephone interviews conducted by study nurses using a standardized symptom score (Table I; available at www.jpeds.com) with high sensitivity for lower respiratory tract infection and particularly reflects the burden of disease and health care utilization. Day and night time respiratory symptom scores range from 0 to 4 , with scores $\geq 3$ indicating severe symptoms (eg, repeated sleep disturbances, admission to hospital, or general practitioner called). The outcome was the overall symptom score calculated as the sum of day and night-time symptom scores (total possible range 0-8).

\section{Breastfeeding}

Mothers were asked weekly about their breastfeeding status until they completely stopped breastfeeding. Any breastfeeding was defined as exclusive breastfeeding, or receiving breast milk and other solids or liquids, and was treated as a binary time-dependent variable (yes or no for each week under observation). Because supplementation with formula and the introduction of solids were not regularly assessed in a standardized manner, these factors were not considered for further analysis. 


\section{$\underline{\text { Risk factors }}$}

Detailed information on risk factors was obtained either at enrollment or during the weekly telephone interviews using a standardized questionnaire; described elsewhere. ${ }^{26}$. Risk factors included maternal history of atopy (defined as either atopic asthma, atopic rhinitis or atopic dermatitis), mode of delivery (vaginal or cesarean delivery), parental educational level (low = less than four years of apprenticeship; middle $=$ at least four years of apprenticeship, and high $=$ tertiary education) as a marker of socioeconomic status, number of older siblings $(0,1$ and $\geq 2)$, child care attendance, maternal smoking during pregnancy, postnatal parental smoking and housing conditions. Cotinine levels were tested in the first urine to validate maternal smoking status. Average weekly air pollution levels in the week preceding the interview were quantitatively measured and modelled, as previously described. ${ }^{8}$

\section{$\underline{\text { Statistical Analyses }}$}

Time-series data for each child consisted of weekly measures of respiratory symptom score, breastfeeding status, and time-dependent variables, e.g. week of age, $\mathrm{PM}_{10}$ exposure, temperature and week of study (includes seasonal variation). The smooth (non-linear) function of week of study also allowed us to control for unmeasured time-varying confounders such as flu epidemics (Figure 1; available at www.jpeds.com). Respiratory symptom scores with a large number of zeroes (ie, weeks without respiratory symptoms) had an overdispersed Poisson distribution with a mean greater than a variance. Thus we analyzed data using the generalized additive mixed-model (GAMM) with quasi-Poisson distribution allowing for overdispersion. To account for possible temporal correlation among respiratory symptoms within each child we included an autoregressive structure with lag 1 . 
We first investigated the relationship between the respiratory symptom score and each exposure of interest adjusting only for week of study (includes seasonal variation), and week of age (simple model). We then adjusted (adjusted model) for exposures of interest and known confounders: sex, birth weight, gestational age, mode of delivery, maternal atopy, number of older siblings, child care attendance, maternal smoking during pregnancy, maternal education, distance to major roads, weekly average of temperature, week of study, week of age and weekly average of $\mathrm{PM}_{10}$. In order to assess the potential effect of modification by breastfeeding on the association between age, perinatal, environmental, hereditary risk factors and respiratory symptoms, we fitted separate regression models by breastfeeding status. We included in the adjusted models the multiplicative interaction term between breastfeeding and exposure of interest to calculate p-value for interaction.

We then repeated the analysis focusing on the first 27 weeks of life. We chose this as the cutoff because it is the median in age distribution in our study sample, and because the protective effect of breastfeeding is stronger in younger infants. Figure 2 (available at $\underline{\text { ww.jpeds.com) }}$ summarizes the statistical strategy.

In the sensitivity analysis, we selected infants without maternal smoking exposure during pregnancy $(\mathrm{N}=402)$ in order to examine the effect of parental postnatal smoking exposure on respiratory morbidity and its modification by breastfeeding.

Estimates were expressed as a risk ratio (RR) with $95 \%$ confidence interval (CI). We calculated p-trend values by applying post hoc ANOVA test. All analyses were performed 
with $\mathrm{R}$ (version 3.0.1) using mgcv package. ${ }^{28,29} \mathrm{~A}$ p-value below 0.05 was considered to be significant. 


\section{Results}

We studied 436 unselected healthy infants with complete information about their breastfeeding status from the BILD-birth cohort study. Population statistics are described in Table II. Results from both the simple and adjusted models for the overall respiratory symptom score during first 27 weeks, and first year, of life are summarized in Tables III and IV (Table IV; available at www.jpeds.com), respectively. The stratified analysis by breastfeeding and sex with $\mathrm{p}$ - value for interaction are displayed in Tables V-VIII (Tables VI, VII, and VIII; available at www.jpeds.com). Additional results are available in the Appendix (available at www.jpeds.com).

Over the first 12 months, breastfeeding was not significantly associated with the respiratory symptom score, in either the simple or adjusted models (Table IV). However, a significant correlation between respiratory symptoms and breastfeeding was found in the first 6 months of life (Table III).

GAMM analysis showed a significant non-linear association between week of age and respiratory symptoms in the first year of life (p-value $<0.001)$. The overall symptom score increased, mainly during the first 27 weeks. After that point, the symptom score did not change considerably (Figure 3; available at www.jpeds.com).

After restricting our sample size to those infants 27 weeks and younger, overall respiratory symptoms were significantly lower in breastfed infants compared with non-breastfed ones (adjusted RR=0.70; 95\% CI, 0.55-0.88; Table III). As a consequence, our later analysis focused on respiratory symptoms during the first 27 weeks of life as a primary outcome due to the strong age-dependent association between breastfeeding and respiratory symptoms. 
Male sex was a significant risk factor (adjusted RR 1.26; 95\% CI, 1.03-1.54; Table III) for overall respiratory symptoms during the first 27 weeks of life. By stratifying according to breastfeeding status, the effect of male sex was observed in breastfed infants $(R R=1.52 ; 95 \%$ CI, 1.21-1.92; Table V), but not in non-breastfed ones with evidence for interaction ( $\mathrm{p}$-value for interaction=0.030). In the sensitivity analysis, we performed the stratification by sex, and observed the protective effect of breastfeeding only in girls $(\mathrm{RR}=0.50 ; 95 \% \mathrm{CI}, 0.35-0.73)$ and not in boys (RR=0.93; 95\% CI, 0.68-1.27) (Table VII).

No significant association was found (Table III) between mode of delivery and respiratory morbidity. When we stratified by breastfeeding status, we observed a nonsignificant reduction of overall respiratory symptoms score in breastfed children born by cesarean $(\mathrm{RR}=0.74 ; 95 \% \mathrm{CI}, 0.53-1.04$; Table V). In contrast, in non-breastfed infants, the risk of having an overall respiratory symptom score 2.86 times higher was observed in the cesarean versus vaginal delivery group (95\% CI, 1.53-5.34; Table V). Further, there was significant interaction between breastfeeding and mode of delivery on respiratory symptoms ( $\mathrm{p}$-value for interaction<0.001).

Gestational age was not significantly associated with respiratory symptoms (Table III). However, in non-breastfed children, significant decrease in respiratory morbidity occurs with an increasing gestational age $(\mathrm{RR}=0.77 ; 95 \% \mathrm{CI}, 0.61-0.97)$. On the other hand, there was no significant relationship between gestational age and respiratory symptoms in breastfed children in the first 27 weeks of age (Table V). There was significant interaction between gestational age and breastfeeding (p-value for interaction<0.001). 
Smoking during the pregnancy was significantly related to respiratory symptoms in the first 27 weeks of life (adjusted $\mathrm{RR}=1.68$; 95\% CI, 1.28-2.21; Table III). A stratified analysis by breastfeeding revealed the highest risk group was those infants who were not breastfed and whose mothers smoked during pregnancy $(\mathrm{RR}=3.51 ; 95 \% \mathrm{CI}, 1.66-7.40)$. The association between maternal smoking during pregnancy and respiratory morbidity in breastfed infants was not significant (Table V). In the adjusted model, the maternal smoking $\times$ breastfeeding interaction was significant ( $\mathrm{p}$-value for interaction=0.040; Table V) indicating a protective effect of breastfeeding against the harmful effects of smoking on respiratory morbidity in offspring.

The adjusted GAMM demonstrated non-significant positive associations of $\mathrm{PM}_{10}$ with respiratory symptoms during first 27 weeks of life, with 1.04 (95\% CI, 0.97-1.17) per 10 $\mu \mathrm{g} / \mathrm{m} 3$ increase in $\mathrm{PM}_{10}$, respectively (Table III). The effect of $\mathrm{PM}_{10}$ was stronger in breastfed infants than in non-breastfed ones (Table V), although the interaction between breastfeeding and $\mathrm{PM}_{10}$ was not significant. 


\section{Discussion}

In this prospective study of healthy infants from a white Central European middle-class population, we investigated the effects of individual risk factors such as age, sex, hereditary risk factors, perinatal, and environmental factors on respiratory symptoms in the first year of life, and the effect modification by any breastfeeding on each of these risk factors separately. We were able to confirm findings from other studies that the known risk factors (male sex, older siblings, and child care) were associated with more respiratory symptoms., 1,14 Maternal smoking during pregnancy and passive parental postnatal tobacco exposure are risk factors for respiratory symptoms in the first year of life. ${ }^{1,2,9,22} \mathrm{PM}_{10}$ exposure in the week preceding the interview tended to be associated with an increase in overall respiratory symptoms during the first year of life, although not significant. ${ }^{8}$

The protective effect of breastfeeding was predominantly seen in the first 6 months of life. This finding is consistent with evidence from several studies in the literature. ${ }^{2,10,12-15}$ and several hypotheses related to the mechanism have been proposed. Most studies have associated the protective effect of breastfeeding with lower susceptibility to viral infections. In a few previous prospective studies it was shown that breastfeeding reduced the occurrence of acute respiratory illness until up to 4 months of life. ${ }^{10,12,13,15}$ This may be partially explained by the higher concentration of the immune-modulating and anti-inflammatory components in early lactation, ${ }^{12,30}$ as well as changes in the microbiota of breast milk. ${ }^{31}$

We found a stronger protective effect of breastfeeding in girls than in boys. There are several studies demonstrating that sex has an influence on the occurrence of respiratory symptoms in breastfed children in the first year of life, ${ }^{16-18}$ but two of those studies are retrospective ${ }^{18}$ and/or cross-sectional. ${ }^{16}$ Several studies explained these phenomena by sex differences in 
early immunity (eg, by differential responses to vaccines). ${ }^{17,}{ }^{18}$ Others hypothesized that human breast milk differently activated the immune system in boys and girls. ${ }^{16}$

The immune system is also involved in the maternal history of asthma and atopy, which are known risk factors for subsequent wheeze in offspring. ${ }^{32}$ However, both infants of atopic mothers and those showing signs of atopic dermatitis (7.3\%) did not show an association with respiratory symptoms in the first year of life; and no evidence of interaction between breastfeeding and maternal atopy or atopic dermatitis of child was observed ( $p$-value $>0.05$ ).

A protective effect of breastfeeding has been reported in a first-born infant, but not in those with older siblings, ${ }^{19}, 33$ with the possible mechanism that increased exposure to microorganisms in infants with older siblings overwhelms the protective effect of the breastfeeding. However, in our study we found no evidence for interaction between breastfeeding and number of older siblings.

We did not identify a relationship between gestational age and respiratory symptoms during the first year of life. Previous studies reported increased risk for neonatal morbidity ${ }^{4}$ and hospitalization $^{5}$ in infants delivered in the early term period (37-38 weeks) vs. the late term period ( $\geq 39$ weeks). However, these studies used different definitions of outcomes and gestational age, and studied different age periods. In our study, respiratory symptoms increase with a decrease in gestational age in non-breastfed infants, but not in breastfed ones. Thus an interaction of gestational age and breastfeeding can be postulated. The underlying mechanism of the reduction of respiratory symptoms by breastfeeding may be associated with immune and non-immune factors in the breast milk influencing the neonatal development of the lungs. ${ }^{34}$ 
A novel and striking finding relates to cesarean delivery, which is a known and poorly understood risk factor for subsequent respiratory symptoms and asthma. Several hypotheses have been raised as to why cesarean birth may be related to later respiratory symptoms. It has been postulated that during vaginal delivery the immune system is specifically stimulated. ${ }^{35}$ Others have hypothesized that bacterial colonization of the airways is modified by the birth mode. ${ }^{36}$ Recent literature strongly focuses on the importance of the bacterial microbiome on the development of respiratory symptoms and asthma in young children, ${ }^{37}$ and breastfeeding is known to modify the airway microbiome in offspring. ${ }^{38}$ We hypothesize that such mechanisms may play a role in our finding in non-breastfed children that the risk of respiratory symptoms is higher after cesarean vs. vaginal delivery.

In our study, outdoor air pollution was estimated by accurately measured and modeled $\mathrm{PM}_{10}$ exposure, adjusted by season and temperature. The stratified analysis showed a stronger, but non-significant effect of $\mathrm{PM}_{10}$ air pollution in breastfed infants. This is in contrast to the findings of Dong et al. ${ }^{20}$ Their retrospective study reported that breastfeeding reduced the effect of $\mathrm{PM}_{10}$ on respiratory symptoms in children 2-5 years of age. Because our findings are observational, we cannot make mechanistic inferences; however chemical contamination of breast milk of mothers exposed to air pollution has been described. ${ }^{39-41}$

Few studies describe the interaction between breastfeeding and maternal smoking on respiratory symptoms. ${ }^{20-23}$ In the present study, we found a modifying effect of breastfeeding on respiratory symptoms induced by prenatal smoking, but not postnatal passive smoking. Furthermore, the greater adverse effect of smoking exposure in non-breastfed infants was observed during the prenatal, rather than the postnatal, period. A possible explanation linking the different effects of smoking exposure and $\mathrm{PM}_{10}$ by breastfeeding may include the difference in tobacco and particulate matter compounds, and the time of 
exposure. Future research needs to obtain information as to when the mother was exposed to smoke while breastfeeding, and investigate the chemical contamination of the breast milk.

In order to study dynamic interactions between contributing factors, large datasets are needed. A prospective study design of 436 children, each with 50-54 observations, leads to 22820 observed weeks. One strength of our study was that we sought to avoid detection bias by prospectively asking mothers weekly whether or not they are breastfeeding. This allowed us to clearly define the outcomes of breastfeeding and assess breastfeeding as a time-varying variable. One difficulty was quantifying the addition of formula supplementation (partial breastfeeding). The method of formula feeding and introduction of solids in our healthy group was heterogeneous and, therefore, statistical power did not allow us to perform a subgroup analysis. Thus we used only the exact time point when mothers completely weaned their children. Comparing exclusive and non-exclusive breastfeeding could reinforce our findings, given that we observed a greater benefit of breastfeeding in exclusively breastfed infants. ${ }^{12,15,17,23}$ Despite the long study period, no systematic changes in the assessment of the exposures and outcomes were observed. A further limitation may be the low to medium levels of air pollution in Switzerland, which made it difficult to compare findings with more polluted areas of the world. Whereas risk factors were chosen a priori based on evidence from previous studies, we did not apply a Bonferroni correction for the number of interaction tests. Even after the Bonferroni correction (0.05/8 interaction tests $=0.00625$ ) the interactions between breastfeeding and gestational age, and mode of delivery remained significant.

Our study suggests that breastfeeding attenuates the effects of risk factors such as sex, age, gestational age, cesarean delivery, and prenatal maternal tobacco smoking in healthy 
term infants. In contrast, there is no evidence suggesting that breastfeeding modifies the association of respiratory symptoms with maternal atopy, child care attendance, older siblings, postnatal passive smoking, or $\mathrm{PM}_{10}$

The common mechanism of the protective effects of breastfeeding needs to be elucidated in future studies. Possible hypotheses may relate to immune development and susceptibility to viral infections. We found that breastfeeding had its strongest protective effect in the first 6 months of life, in girls, and in infants exposed to maternal tobacco smoking. The most striking effect, however, was that infants born by cesarean delivery may profit the most from breastfeeding. We hypothesize that altered immune development or development of the airway microbiota after cesarean birth may be mechanisms of interest. Confirmation of these findings in future studies could have an important impact on health policy. 


\section{Acknowledgments}

The authors would like to thank our study nurses, Monika Graf, Sandra Luescher, and Linda

Beul-Béguin for performing the weekly telephone interviews with the parents (Division of

Respiratory Medicine, Department of Pediatrics, Inselspital and University of Bern, Bern,

Switzerland). We are grateful to all study participants and their families for their participation.

We would also like to thank Karine Landgren Hugentobler for reading the manuscript. 


\section{References}

[1] Latzin P, Frey U, Roiha H, Baldwin D, Regamey N, Strippoli MP, et al. Prospectively assessed incidence, severity, and determinants of respiratory symptoms in the first year of life. Pediatric pulmonology. 2007;42:41-50.

[2] Koch A, Mølbak K, Homøe P, Sørensen P, Hjuler T, Olesen ME, et al. Risk Factors for Acute Respiratory Tract Infections in Young Greenlandic Children. American Journal of Epidemiology. 2003;158:374-84.

[3] Hansen AK, Wisborg K, Uldbjerg N, Henriksen TB. Risk of respiratory morbidity in term infants delivered by elective caesarean section: cohort study. Bmj. 2008;336:85-7.

[4] Ghartey K, Coletta J, Lizarraga L, Murphy E, Ananth CV, Gyamfi-Bannerman C. Neonatal respiratory morbidity in the early term delivery. American Journal of Obstetrics and Gynecology. 2012;207:292.e1-.e4.

[5] Paranjothy S, Dunstan F, Watkins WJ, Hyatt M, Demmler JC, Lyons RA, et al. Gestational age, birth weight, and risk of respiratory hospital admission in childhood. Pediatrics. 2013; 132:e1562-e9.

[6] Miller EK, Williams JV, Gebretsadik T, Carroll KN, Dupont WD, Mohamed YA, et al. Host and viral factors associated with severity of human rhinovirus-associated infant respiratory tract illness. Journal of Allergy and Clinical Immunology. 2011;127:883-91. [7] Carroll KN, Gebretsadik T, Minton P, Woodward K, Liu Z, Miller EK, et al. Influence of maternal asthma on the cause and severity of infant acute respiratory tract infections. Journal of Allergy and Clinical Immunology. 2012;129:1236-42.

[8] Stern G, Latzin P, Röösli M, Fuchs O, Proietti E, Kuehni C, et al. A prospective study of the impact of air pollution on respiratory symptoms and infections in infants. American journal of respiratory and critical care medicine. 2013;187:1341-8. 
[9] Pattenden S, Antova T, Neuberger M, Nikiforov B, De Sario M, Grize L, et al. Parental smoking and children's respiratory health: independent effects of prenatal and postnatal exposure. Tobacco Control. 2006;15:294-301.

[10] Howie PW, Forsyth JS, Simon AO, Clark A, Florey CDV. Protective Effect Of Breast Feeding Against Infection. BMJ: British Medical Journal. 1990;300:11-6.

[11] Ladomenou F, Moschandreas J, Kafatos A, Tselentis Y, Galanakis E. Protective effect of exclusive breastfeeding against infections during infancy: a prospective study. Archives of Disease in Childhood. 2010.

[12] Cushing AH, Samet JM, Lambert WE, Skipper BJ, Hunt WC, Young SA, et al. Breastfeeding Reduces Risk of Respiratory Illness in Infants. American Journal of Epidemiology. 1998;147:863-70.

[13] Wright AL, Holberg CJ, Martinez FD, Morgan WJ, Taussig LM. Breast feeding and lower respiratory tract illness in the first year of life. Group Health Medical Associates. BMJ : British Medical Journal. 1989;299:946-9.

[14] von Linstow ML, Holst KK, Larsen K, Koch A, Andersen PK, Høgh B. Acute respiratory symptoms and general illness during the first year of life: A population-based birth cohort study. Pediatric pulmonology. 2008;43:584-93.

[15] López-Alarcón M, Villalpando S, Fajardo A. Breast-Feeding Lowers the Frequency and Duration of Acute Respiratory Infection and Diarrhea in Infants under Six Months of Age. The Journal of Nutrition. 1997;127:436-43.

[16] Libster R, Hortoneda JB, Laham FR, Casellas JM, Israele V, Polack NR, et al. Breastfeeding prevents severe disease in full term female infants with acute respiratory infection. The Pediatric infectious disease journal. 2009;28:131-4. [17] Klein MI, Bergel E, Gibbons L, Coviello S, Bauer G, Benitez A, et al. Differential Gender Response to Respiratory Infections and to the Protective Effect of Breast Milk in Preterm Infants. Pediatrics. 2008;121:e1510-e6. 
[18] Sinha A, Madden J, Ross-Degnan D, Soumerai S, Platt R. Reduced Risk of Neonatal Respiratory Infections Among Breastfed Girls but Not Boys. Pediatrics. 2003;112:e303.

[19] Pettigrew MM, Khodaee M, Gillespie B, Schwartz K, Bobo JK, Foxman B. Duration of breastfeeding, daycare, and physician visits among infants 6 months and younger. Annals of epidemiology. 2003;13:431-5.

[20] Dong G-H, Qian Z, Liu M-M, Wang D, Ren W-H, Bawa S, et al. Breastfeeding as a Modifier of the Respiratory Effects of Air Pollution in Children. Epidemiology. 2013;24:38794 10.1097/EDE.0b013e3182877eb8.

[21] Nafstad P, Jaakkola J, Hagen J, Botten G, Kongerud J. Breastfeeding, maternal smoking and lower respiratory tract infections. European Respiratory Journal. 1996;9:2623-9.

[22] Woodward A, Douglas RM, Graham NM, Miles H. Acute respiratory illness in Adelaide children: breast feeding modifies the effect of passive smoking. Journal of Epidemiology and Community Health. 1990;44:224-30.

[23] Rylander E, Pershagen G, Eriksson M, Nordvall L. Parental smoking and other risk factors for wheezing bronchitis in children. Eur J Epidemiol. 1993;9:517-26.

[24] Scott J, Aitkin I, Binns C, Aroni R. Factors associated with the duration of breastfeeding amongst women in Perth, Australia. Acta Paediatrica. 1999;88:416-21.

[25] Thulier D, Mercer J. Variables associated with breastfeeding duration. Journal of Obstetric, Gynecologic, \& Neonatal Nursing. 2009;38:259-68.

[26] Fuchs O, Latzin P, Kuehni CE, Frey U. Cohort profile: the Bern infant lung development cohort. International journal of epidemiology. 2012;41:366-76.

[27] Silverman M, Wang M, Hunter G, Taub N. Episodic viral wheeze in preschool children: effect of topical nasal corticosteroid prophylaxis. Thorax. 2003;58:431-4.

[28] Team RDC. R Development Core Team (2013). R: A language and environment for statistical computing. R Foundation for Statistical Computing, Vienna, Austria. ISBN 3- 
900051-07-0, URL http://www.R-project.org. R Foundation for Statistical Computing, Vienna, Austria.

[29] Wood S. Generalized additive models: an introduction with R: CRC press; 2006.

[30] Ballard O, Morrow AL. Human Milk Composition: Nutrients and Bioactive Factors. Pediatric Clinics of North America. 2013;60:49-74.

[31] Khodayar-Pardo P, Mira-Pascual L, Collado M, Martínez-Costa C. Impact of lactation stage, gestational age and mode of delivery on breast milk microbiota. Journal of Perinatology. 2014.

[32] Sherriff A, Peters TJ, Henderson J, Strachan D, Team aTAS. Risk factor associations with wheezing patterns in children followed longitudinally from birth to $3 \frac{1}{2}$ years. International Journal of Epidemiology. 2001;30:1473-84.

[33] Raisler J, Alexander C, O'Campo P. Breast-feeding and infant illness: a dose-response relationship? American Journal of Public Health. 1999;89:25-30.

[34] Waidyatillake NT, Allen KJ, Lodge CJ, Dharmage SC, Abramson MJ, Simpson JA, et al. The impact of breastfeeding on lung development and function: a systematic review. Expert review of clinical immunology. 2013;9:1253-65.

[35] Belderbos M, Houben M, Van Bleek G, Schuijff L, Van Uden N, Bloemen-Carlier E, et al. Breastfeeding modulates neonatal innate immune responses: a prospective birth cohort study. Pediatric Allergy and Immunology. 2012;23:65-74.

[36] Dominguez-Bello MG, Costello EK, Contreras M, Magris M, Hidalgo G, Fierer N, et al. Delivery mode shapes the acquisition and structure of the initial microbiota across multiple body habitats in newborns. Proceedings of the National Academy of Sciences. 2010;107:11971-5.

[37] van Nimwegen FA, Penders J, Stobberingh EE, Postma DS, Koppelman GH, Kerkhof M, et al. Mode and place of delivery, gastrointestinal microbiota, and their influence on asthma and atopy. Journal of Allergy and Clinical Immunology. 2011;128:948-55.e3. 
[38] Biesbroek G, Bosch AA, Wang X, Keijser BJ, Veenhoven RH, Sanders EA, et al. The impact of breastfeeding on nasopharyngeal microbial communities in infants. American journal of respiratory and critical care medicine. 2014;190:298-308.

[39] Kishikawa N, Wada M, Kuroda N, Akiyama S, Nakashima K. Determination of polycyclic aromatic hydrocarbons in milk samples by high-performance liquid chromatography with fluorescence detection. Journal of Chromatography B. 2003;789:25764.

[40] Zanieri L, Galvan P, Checchini L, Cincinelli A, Lepri L, Donzelli GP, et al. Polycyclic aromatic hydrocarbons (PAHs) in human milk from Italian women: Influence of cigarette smoking and residential area. Chemosphere. 2007;67:1265-74.

[41] Landrigan PJ, Sonawane B, Mattison D, McCally M, Garg A. Chemical contaminants in breast milk and their impacts on children's health: an overview. Environmental Health Perspectives. 2002;110:A313. 


\section{Figure legend}

Figure 2. Flowchart of statistical analysis (first 27 weeks). Results are presented in a twoway but congruent manner. Right side: the results of the generalized additive mixed-model with quasi-Poisson distribution describing the effect of the risk factors on symptoms and their interactions with breastfeeding (BF) (Table III) Left side: the association of the overall respiratory symptom score with risk factors stratified by breastfeeding status (see also table 3). Abbreviations: BF, breastfeeding; PM, particulate matter smaller than about 10 micrometres; GA, gestational age.

Figure 1, online only. Schematic representation of relationship between breastfeeding and respiratory symptoms in the first year of life. BF represents the breastfeeding status and RS represents the overall respiratory symptoms score for each week under observation (the possible range from 1 to 52/53).

Figure 3, online only. Change in the risk of developing overall respiratory symptoms during the first year of life $(\mathrm{df}=4.24, \mathrm{p}$-value $<0.0001)$. The shaded regions denote the $95 \% \mathrm{CI}$. Results were obtained from the generalized additive mixed-model adjusted for sex, gestational age, mode of delivery, breastfeeding, birth weight, maternal atopy, older siblings, child care, maternal smoking during the pregnancy, temperature, week of study, distance to major roads, maternal education, and $\mathrm{PM}_{10}$.

Abbreviations: RR, relative risk; PM, particulate matter smaller than about 10 micrometres. Table 1, online only. Symptom Score used in Weekly Phone Calls.

Table 4, online only. Analysis of factors associated with the overall respiratory symptom score during 1 year of life $(n=22,820)$. 
Table 6, online only. Association of the overall respiratory symptom score with risk factors stratified by breastfeeding status: 1 year of life.

Table 7, online only. Adjusted association ${ }^{\mathrm{a}}$ of the overall respiratory symptom score with the breastfeeding stratified by sex (first 27 weeks).

Table 8, online only. Adjusted ${ }^{\mathrm{a}}$ association of the postnatal parental smoking with overall respiratory symptom score in infants without maternal smoking exposure during the pregnancy $(\mathrm{N}=402)$ (first 27 weeks of life).

multivariable model. 


\section{Appendix}

Of the 436 participants, 9 observations were excluded from the sample: 7 infants and 3 twin siblings did not complete the 12 months of follow-up; we did not have information about the mode of delivery, older siblings, or childcare, for 3 of the infants; and we did not have home address information for another 3 infants. Population statistics are described in detail in Table II. The mean duration of breastfeeding was 34.7 weeks; it was shorter in smoking mothers than in non-smoking mothers (Table II). Six (1.38\%) infants were not breastfed at all.

Protective effects of breastfeeding against the harmful impact of tobacco exposure on $\underline{\text { respiratory symptoms }}$

$A$ sensitivity analysis with the additional adjustment for parental postnatal smoking exposure indicated that the effect of maternal smoking during pregnancy on overall respiratory symptoms was slightly attenuated in breastfed $(\mathrm{RR}=1.24 ; 95 \% \mathrm{CI}, 0.85-1.80)$ and nonbreastfed infants $(\mathrm{RR}=2.72 ; 95 \% \mathrm{CI}, 1.18-6.30)$. The interaction between breastfeeding and maternal smoking in pregnancy remained significant ( $p$-value for interaction=0.044) (data not shown).

In the subgroup of the infants without maternal smoking exposure during pregnancy $(n=402)$, postnatal parental smoking was associated with a 1.35 increased risk of overall respiratory symptom score in the first 27 weeks of life (95\% CI, 1.06-1.71; Table VIII). Here, we found no evidence for interaction between postnatal parental smoking exposure and breastfeeding in relation to respiratory symptoms ( $\mathrm{p}$-value for interaction=0.210; Table VIII). However, the breastfed infants tended to have fewer respiratory symptoms $(\mathrm{RR}=1.25 ; 95 \% \mathrm{CI}, 0.94-1.65)$ than non-breastfed ones ( $R R=1.76 ; 95 \% \mathrm{CI}, 0.88-3.47)$ (Table VIII).

\section{Breastfeeding and other factors}


Being in childcare and having older siblings are important risk factors for developing respiratory symptoms in infancy (Table III). In the interaction models we did not find evidence for interaction between either number of older siblings and breastfeeding, or attending childcare and breastfeeding, on respiratory symptoms (Table V).

We additionally performed the analysis including week of childcare as a time-dependent variable over the entire first year of life, we found that in the first 3 months there was a lack of exposure (almost none of the infants were in child care); at the end of the first year, very few infants were still breastfeed. Thus, in order to have enough statistical power with this type of analysis we focussed on the time period between 12 and 36 weeks of age. In performing the analysis with this timeframe, we produced similar results to our first analysis, where we treated (child care) as a time independent categorical variable (data not shown).

Maternal history of atopy (Table III) and maternal asthma (data not shown) did not have an impact on respiratory morbidity in the first year of life. There was no interaction between breastfeeding and maternal atopy (Table V) or maternal asthma (data not shown). 
Table 1. Symptom Score used in Weekly Phone Calls ${ }^{\mathrm{a}}$

\begin{tabular}{cll}
\hline Symptom score & $\begin{array}{c}\text { Daytime symptoms (cough, wheeze, or } \\
\text { breathing difficulties) }\end{array}$ & \multicolumn{1}{c}{$\begin{array}{c}\text { Night-time symptoms (cough, wheeze, } \\
\text { or breathing difficulties) }\end{array}$} \\
\hline 0 & None & None \\
1 & Slight; no treatment given & Slight; sleep not disturbed \\
2 & Required treatment but no outside help & $\begin{array}{l}\text { Sleep disturbed once; no help required } \\
3\end{array}$ \\
4 & Severe; required help from GP & Sleep disturbed more than once or child needed help \\
Very severe; admitted to hospital & Sleep very disturbed or GP called \\
\hline
\end{tabular}

${ }^{\mathrm{a}}$ Published with permission of BMJ publishing group 
Table 2. Characteristics of the study population $(\mathrm{N}=436)$.

\section{Summary statistics}

\section{Anthropometrics}

Boys, n (\%)

$235(53.9 \%)$

Birth weight, mean (sd), kg

Length, mean (sd), cm $49(2.0)$

Gestational age, mean (sd), week

$39.8(1.1)$

\section{Respiratory symptoms, mean (sd)}

1 year of life

Weeks with overall symptoms

Overall respiratory symptom score

27 weeks of life

Weeks with overall symptoms

Overall respiratory symptom score

$0.13(0.6)$

\section{Duration of breastfeeding (week)}

Breastfeeding, mean (sd)

Boys, mean (sd)

Girls, mean (sd)

No maternal smoking in pregnancy, mean (sd)

$25.8(16.4)$

Maternal smoking in pregnancy, mean (sd)

Vaginal delivery, mean (sd)

Caesarean section, mean (sd)

$36.1(14)$

\section{Risk factors}

Number of older siblings, $\mathrm{n}(\%)$ :

$$
1
$$

$165(37.8 \%)$

$\geq 2$

$72(16.5 \%)$

Child care, n (\%)

$98(22.5 \%)$

Maternal asthma, n (\%)

$49(11.2 \%)$

Maternal atopy $^{\mathrm{a}}, \mathrm{n}(\%)$

$143(32.8 \%)$

Maternal smoking during pregnancy, n (\%)

$42(9.6 \%)$

Parental smoking in first year of life, $\mathrm{n}(\%)$

$89(20.4 \%)$

Cesarean section, $\mathrm{n}(\%)$

$69(15.8 \%)$

\section{Environmental Exposure}

\section{Outdoor exposure}

Distance to major roads, mean (sd)

$366.1(508.3)$

Weekly mean $\mathrm{PM}_{10}$, mean (sd), $\mu \mathrm{g} / \mathrm{m}^{3}$

$19.1(9.9)$ 
Weekly mean $\mathrm{NO}_{2}$, mean (sd), $\mu \mathrm{g} / \mathrm{m}^{3}$

Weekly mean temperature, mean (sd), C

\section{Indoor Exposure}

Gas stove in the home $(\mathrm{n}=414), \mathrm{n}(\%)$

$32(7.7 \%)$

Open fireplace in the home $(\mathrm{n}=414), \mathrm{n}(\%)$

Educational status, n (\%):

Low

$118(27 \%)$

Middle

$148(33.9 \%)$

High
$15.1(7.3)$

$9.7(7.3)$
$170(39.1 \%)$

Abbreviations: $\mathrm{N}$, number of children

a defined as either atopic asthma, atopic rhinitis, or atopic dermatitis 
Table 3. Analysis of factors associated with the overall respiratory symptom score during the

first 27 weeks $(n=11,365)$.

\begin{tabular}{|c|c|c|c|c|c|c|c|}
\hline \multirow[b]{2}{*}{ Variable } & \multirow{2}{*}{$\begin{array}{c}\text { Mean of } \\
\text { symptom } \\
\text { score }^{\mathrm{a}}\end{array}$} & \multicolumn{3}{|c|}{ Simple $^{b}$ model } & \multicolumn{3}{|c|}{ Adjusted $^{\mathrm{c}}$ model } \\
\hline & & $\mathbf{R R}$ & $95 \% \mathrm{CI}$ & p-value & $\mathbf{R R}$ & $95 \% \mathrm{CI}$ & p-value \\
\hline Breastfeeding & & & & $<0.001$ & & & 0.002 \\
\hline no & 0.27 & 1.0 & Reference & & 1.0 & Reference & \\
\hline yes & 0.12 & 0.63 & $0.50-0.80$ & & 0.70 & $0.55-0.88$ & \\
\hline Sex & & & & 0.009 & & & 0.024 \\
\hline girls & 0.11 & 1.0 & Reference & & 1.0 & Reference & \\
\hline boys & 0.16 & 1.32 & $1.07-1.64$ & & 1.26 & $1.03-1.54$ & \\
\hline Mode of delivery & & & & 0.828 & & & 0.680 \\
\hline vaginal & 0.14 & 1.0 & Reference & & 1.0 & Reference & \\
\hline cesarean & 0.13 & 0.97 & $0.72-1.30$ & & 1.06 & $0.81-1.39$ & \\
\hline Maternal atopy & & & & 0.330 & & & 0.405 \\
\hline no & 0.14 & 1.0 & Reference & & 1.0 & Reference & \\
\hline yes & 0.13 & 0.89 & $0.71-1.12$ & & 0.91 & $0.74-1.13$ & \\
\hline Number of older siblings & & & & $<0.001$ & & & $<0.001$ \\
\hline 0 & 0.08 & 1.0 & Reference & & 1.0 & Reference & \\
\hline 1 & 0.17 & 1.97 & $1.55-2.50$ & & 1.91 & $1.35-2.16$ & \\
\hline$\geq 2$ & 0.21 & 2.38 & $1.81-3.12$ & & 2.83 & $2.11-3.81$ & \\
\hline Child care & & & & 0.523 & & & 0.045 \\
\hline no & 0.14 & 1.0 & Reference & & 1.0 & Reference & \\
\hline yes & 0.15 & 1.08 & $0.85-1.38$ & & 1.27 & $1.01-1.61$ & \\
\hline $\begin{array}{l}\text { Maternal smoking in } \\
\text { pregnancy }\end{array}$ & & & & $<0.001$ & & & $<0.001$ \\
\hline no & 0.12 & 1.0 & Reference & & 1.0 & Reference & \\
\hline yes & 0.28 & 2.19 & $1.67-2.87$ & & 1.68 & $1.28-2.21$ & \\
\hline Gestational age, weeks & 0.13 & 0.98 & $0.89-1.07$ & 0.620 & 0.97 & $0.88-1.07$ & 0.564 \\
\hline $\mathrm{PM}_{10}^{\mathrm{d}}$ & 0.13 & 1.13 & $1.05-1.22$ & 0.002 & 1.05 & $0.97-1.14$ & 0.209 \\
\hline
\end{tabular}

Abbreviations: n, number of weeks under observation; CI, confidence interval; RR, relative risk; PM, particulate matter smaller than about 10 micrometers.

aunadjusted mean of the overall symptom score.

Estimates derived from generalized additive mixed-model with quasi-Poisson distribution:

badjusted for week of study (seasonal variation) and week of age;

${ }^{c}$ adjusted for all variables in the table and for birth weight, maternal atopy, maternal education, older siblings, child care, weekly average of temperature, week of study (seasonal variation), week of age and distance to major roads.

${ }^{\mathrm{d}} \mathrm{RR}$ for $10 \mu \mathrm{g} / \mathrm{m}^{3}$ increase in the level of $\mathrm{PM}_{10}$. 
Table 4. Analysis of factors associated with the overall respiratory symptom score during 1 year of life $(n=22,820)$.

\begin{tabular}{|c|c|c|c|c|c|c|c|}
\hline \multirow[b]{2}{*}{ Variable } & \multirow{2}{*}{$\begin{array}{c}\text { Mean of } \\
\text { symptom }^{\text {score }}\end{array}$} & \multicolumn{3}{|c|}{ Simple $^{\mathrm{b}}$ model } & \multicolumn{3}{|c|}{ Adjusted $^{\mathrm{c}}$ model } \\
\hline & & $\mathbf{R R}$ & $95 \% \mathrm{CI}$ & p-value & $\mathbf{R R}$ & $95 \% \mathrm{CI}$ & p-value \\
\hline Breastfeeding & & & & 0.403 & & & 0.605 \\
\hline no & 0.35 & 1.0 & Reference & & 1.0 & Reference & \\
\hline yes & 0.21 & 0.95 & $0.83-1.08$ & & 0.97 & $0.85-1.10$ & \\
\hline Sex & & & & $<0.001$ & & & 0.001 \\
\hline Girls & 0.22 & 1.0 & Reference & & 1.0 & Reference & \\
\hline Boys & 0.29 & 1.32 & $1.18-1.49$ & & 1.22 & $1.09-1.38$ & \\
\hline Mode of delivery & & & & 0.107 & & & 0.106 \\
\hline Vaginal & 0.26 & 1.0 & Reference & & 1.0 & Reference & \\
\hline Cesarean & 0.23 & 0.87 & $0.74-1.03$ & & 0.88 & $0.74-1.03$ & \\
\hline Maternal atopy & & & & 0.503 & & & 0.599 \\
\hline no & 0.26 & 1.0 & Reference & & 1.0 & Reference & \\
\hline yes & 0.24 & 0.96 & 0.84-1.09 & & 0.97 & $0.86-1.09$ & \\
\hline Number of older siblings & & & & $<0.001$ & & & $<0.001$ \\
\hline 0 & 0.20 & 1.0 & Reference & & 1.0 & Reference & \\
\hline 1 & 0.30 & 1.50 & $1.32-1.70$ & & 1.42 & $1.25-1.62$ & \\
\hline$\geq 2$ & 0.31 & 1.54 & $1.31-1.80$ & & 1.57 & $1.33-1.85$ & \\
\hline Child care & & & & $<0.001$ & & & $<0.001$ \\
\hline no & 0.23 & 1.0 & Reference & & 1.0 & Reference & \\
\hline yes & 0.32 & 1.45 & $1.28-1.64$ & & 1.53 & $1.35-1.74$ & \\
\hline $\begin{array}{l}\text { Maternal smoking in } \\
\text { pregnancy }\end{array}$ & & & & 0.078 & & & 0.052 \\
\hline no & 0.25 & 1.0 & Reference & & 1.0 & Reference & \\
\hline yes & 0.30 & 1.18 & $0.98-1.43$ & & 1.21 & $0.99-1.47$ & \\
\hline Gestational age, weeks & 0.26 & 0.95 & $0.90-1.00$ & 0.051 & 0.95 & $0.90-1.002$ & 0.060 \\
\hline $\mathrm{PM}_{10}^{\mathrm{d}}$ & 0.26 & 1.10 & $1.06-1.15$ & $<0.001$ & 1.04 & $0.99-1.08$ & 0.087 \\
\hline
\end{tabular}

Abbreviations: $\mathrm{n}$, number of weeks under observation; CI, confidence interval; RR, relative risk; PM, particulate matter smaller than about 10 micrometres.

anadjusted mean of the overall symptom score.

Estimates derived from generalized additive mixed-model with quasi-Poisson distribution:

badjusted for week of study (seasonal variation) and week of age;

'adjusted for all variables in the table and for birth weight, maternal atopy, maternal education, older siblings, child care, weekly average of temperature, week of study (seasonal variation), week of age and distance to major roads.

${ }^{\mathrm{d}} \mathrm{RR}$ for $10 \mu \mathrm{g} / \mathrm{m}^{3}$ increase in the level of $\mathrm{PM}_{10}$ 
Table 5. Association of the overall respiratory symptom score with risk factors stratified by breastfeeding status: first 27 weeks.

\begin{tabular}{|c|c|c|c|c|c|c|c|}
\hline & & & Bre & ding & & & \\
\hline & & $(\mathbf{n}=\mathbf{1 0}$, & & & $\mathrm{n}=\mathbf{1 , 5}$ & & p-value for \\
\hline Exposure & $\begin{array}{l}\text { Mean of } \\
\text { symptom } \\
\text { score }^{\mathrm{a}}\end{array}$ & $\mathbf{R R}^{\mathbf{b}}$ & $95 \% \mathrm{CI}^{\mathrm{b}}$ & $\begin{array}{l}\text { Mean of } \\
\text { symptom } \\
\text { score }^{\mathrm{a}}\end{array}$ & $\mathbf{R R}^{\mathbf{b}}$ & $95 \% \mathrm{CI}^{\mathrm{b}}$ & interaction $^{c}$ \\
\hline Sex & & & & & & & 0.029 \\
\hline girls & 0.08 & 1.0 & Reference & 0.31 & 1.0 & Reference & \\
\hline boys & 0.15 & 1.52 & $1.21-1.92$ & 0.23 & 0.73 & $0.43-1.24$ & \\
\hline Mode of delivery & & & & & & & $<0.001$ \\
\hline vaginal & 0.13 & 1.0 & Reference & 0.22 & 1.0 & Reference & \\
\hline cesarean & 0.08 & 0.74 & $0.53-1.04$ & 0.57 & 2.86 & $1.53-5.34$ & \\
\hline Maternal atopy & & & & & & & 0.329 \\
\hline no & 0.13 & 1.0 & Reference & 0.28 & 1.0 & Reference & \\
\hline yes & 0.11 & 0.83 & $0.66-1.06$ & 0.25 & 1.18 & $0.70-1.96$ & \\
\hline Number of older sibling & & & & & & & 0.342 \\
\hline 0 & 0.07 & 1.0 & Reference & 0.19 & 1.0 & Reference & \\
\hline 1 & 0.14 & 2.03 & $1.56-2.64$ & 0.29 & 0.96 & $0.54-1.71$ & \\
\hline$\geq 2$ & 0.19 & 2.44 & $1.80-3.32$ & 0.43 & 1.55 & $0.74-3.23$ & \\
\hline Child care & & & & & & & 0.945 \\
\hline no & 0.12 & 1.0 & Reference & 0.26 & 1.0 & Reference & \\
\hline yes & 0.13 & 1.17 & $0.90-1.52$ & 0.29 & 1.58 & $0.84-2.96$ & \\
\hline $\begin{array}{l}\text { Maternal smoking in } \\
\text { pregnancy }\end{array}$ & & & & & & & 0.040 \\
\hline no & 0.11 & 1.0 & Reference & 0.20 & 1.0 & Reference & \\
\hline yes & 0.19 & 1.32 & $0.93-1.86$ & 0.53 & 3.51 & $1.66-7.40$ & \\
\hline Gestational age, weeks & 0.12 & 1.09 & $0.97-1.21$ & 0.27 & 0.77 & $0.61-0.97$ & $<0.001$ \\
\hline $\mathrm{PM}_{10}^{\mathrm{d}}$ & 0.12 & 1.08 & $0.99-1.17$ & 0.27 & 0.93 & $0.76-1.14$ & 0.101 \\
\hline
\end{tabular}

Abbreviations: $\mathrm{n}$, number of weeks under observation ; CI, confidence interval; $\mathrm{RR}$, relative risk; PM particulate matter smaller than about 10 micrometres.

${ }^{a}$ unadjusted mean of the overall symptom score.

${ }^{\mathrm{b}} \mathrm{RR}$ and $95 \% \mathrm{CI}$ derived from generalized additive mixed-model with quasi-Poisson distribution adjusted for all variables in the table and for birth weight, maternal atopy, maternal education, older siblings, child care, weekly average of temperature, week of study (seasonal variation), week of age and distance to major roads. ${ }^{\mathrm{c}} \mathrm{p}$-value for interaction. Interaction was tested by adding the product between the breastfeeding and corresponding exposure in the adjusted model.

${ }^{\mathrm{d}} \mathrm{RR}$ for $10 \mu \mathrm{g} / \mathrm{m}^{3}$ increase in the level of $\mathrm{PM}_{10}$ 
Table 6. Association of the overall respiratory symptom score with risk factors stratified by breastfeeding status: 1 year of life.

\begin{tabular}{|c|c|c|c|c|c|c|c|}
\hline \multirow[b]{3}{*}{ Exposure } & \multicolumn{6}{|c|}{ Breastfed } & \multirow[b]{3}{*}{$\begin{array}{l}\text { p-value for } \\
\text { interaction }^{c}\end{array}$} \\
\hline & \multicolumn{3}{|c|}{ Yes $(n=15,152)$} & \multicolumn{3}{|c|}{ No $(n=7,668)$} & \\
\hline & $\begin{array}{c}\text { Mean of } \\
\text { symptom } \\
\text { score }^{\mathrm{a}}\end{array}$ & $\mathbf{R R}^{\mathbf{b}}$ & $95 \% \mathrm{CI}^{\mathrm{b}}$ & $\begin{array}{c}\text { Mean of } \\
\text { symptom } \\
\text { score }^{\mathrm{a}}\end{array}$ & $\mathbf{R R}^{\mathbf{b}}$ & $95 \% \mathrm{CI}^{\mathrm{b}}$ & \\
\hline Sex & & & & & & & 0.014 \\
\hline Girls & 0.16 & 1.0 & Reference & 0.32 & 1.0 & Reference & \\
\hline Boys & 0.24 & 1.40 & $1.21-1.63$ & 0.37 & 1.03 & $0.86-1.24$ & \\
\hline Mode of delivery & & & & & & & 0.012 \\
\hline Vaginal & 0.22 & 1.0 & Reference & 0.35 & 1.0 & Reference & \\
\hline Cesarean & 0.15 & 0.72 & $0.58-0.90$ & 0.40 & 1.02 & $0.80-1.30$ & \\
\hline Maternal atopy & & & & & & & 0.372 \\
\hline no & 0.22 & 1.0 & Reference & 0.36 & 1.0 & Reference & \\
\hline yes & 0.18 & 0.91 & $0.78-1.07$ & 0.35 & 1.04 & $0.86-1.26$ & \\
\hline Number of older siblings & & & & & & & 0.754 \\
\hline 0 & 0.16 & 1.0 & Reference & 0.28 & 1.0 & Reference & \\
\hline 1 & 0.24 & 1.51 & $1.27-1.79$ & 0.40 & 1.34 & $1.10-1.64$ & \\
\hline$\geq 2$ & 0.26 & 1.64 & $1.33-2.01$ & 0.43 & 1.51 & $1.16-1.98$ & \\
\hline Child care & & & & & & & 0.959 \\
\hline no & 0.19 & 1.0 & Reference & 0.32 & 1.0 & Reference & \\
\hline yes & 0.27 & 1.48 & $1.26-1.75$ & 0.46 & 1.53 & $1.25-1.87$ & \\
\hline $\begin{array}{l}\text { Maternal smoking in } \\
\text { pregnancy }\end{array}$ & & & & & & & 0.872 \\
\hline yes & 0.20 & 1.0 & Reference & 0.35 & 1.0 & Reference & \\
\hline no & 0.21 & 1.17 & $0.88-1.55$ & 0.39 & 1.31 & $0.99-1.72$ & \\
\hline Gestational age, weeks & 0.21 & 1.01 & 0.94-1.09 & 0.35 & 0.89 & $0.82-0.97$ & 0.032 \\
\hline $\mathrm{PM}_{10}^{\mathrm{d}}$ & 0.21 & 1.06 & $1.00-1.12$ & 0.35 & 1.02 & $0.96-1.08$ & 0.296 \\
\hline $\begin{array}{l}\text { Abbreviations: } \mathrm{n} \text {, numbe } \\
\text { matter smaller than about } \\
{ }^{\mathrm{a}} \text { unadjusted mean of the } \\
{ }^{\mathrm{b}} \mathrm{RR} \text { and } 95 \% \mathrm{CI} \text { derived } \\
\text { variables in the table and } \\
\text { average of temperature, } \\
{ }^{c} \text { p-value for interaction. } \\
\text { corresponding exposure } \\
{ }^{\mathrm{d}} \mathrm{RR} \text { for } 10 \mu \mathrm{g} / \mathrm{m}^{3} \text { increas }\end{array}$ & $\begin{array}{l}\text { of weeks un } \\
0 \text { micrometı } \\
\text { verall sympt } \\
\text { om generali } \\
\text { or birth weig } \\
\text { eek of study } \\
\text { teraction wa } \\
\text { the adjusted } \\
\text { in the level }\end{array}$ & $\begin{array}{l}\text { er obst } \\
\text { es. } \\
\text { m scor } \\
\text { ed add } \\
\text { t, mat } \\
\text { season } \\
\text { tested } \\
\text { model. } \\
\text { f }_{10}\end{array}$ & $\begin{array}{l}\text { vation; CI, } \\
\text { ive mixed-n } \\
\text { nal atopy, } \\
\text { l variation), } \\
\text { y adding th }\end{array}$ & $\begin{array}{l}\text { dence interv } \\
\text { with quasi } \\
\text { nal educatio } \\
\mathrm{k} \text { of age and } \\
\text { duct betwee }\end{array}$ & $\begin{array}{l}\text { oisson } \\
\text { older } \\
\text { istanc } \\
\text { the br }\end{array}$ & $\begin{array}{l}\text { lative risk; } P \\
\text { istribution a } \\
\text { blings, child } \\
\text { o major roa } \\
\text { stfeeding an }\end{array}$ & $\begin{array}{l}\text { M particulate } \\
\text { justed for all } \\
\text { care, weekly } \\
\text { s. } \\
\text { i }\end{array}$ \\
\hline
\end{tabular}


Table 7. Adjusted association ${ }^{\mathrm{a}}$ of the overall respiratory symptom score with the breastfeeding stratified by sex (first 27 weeks)

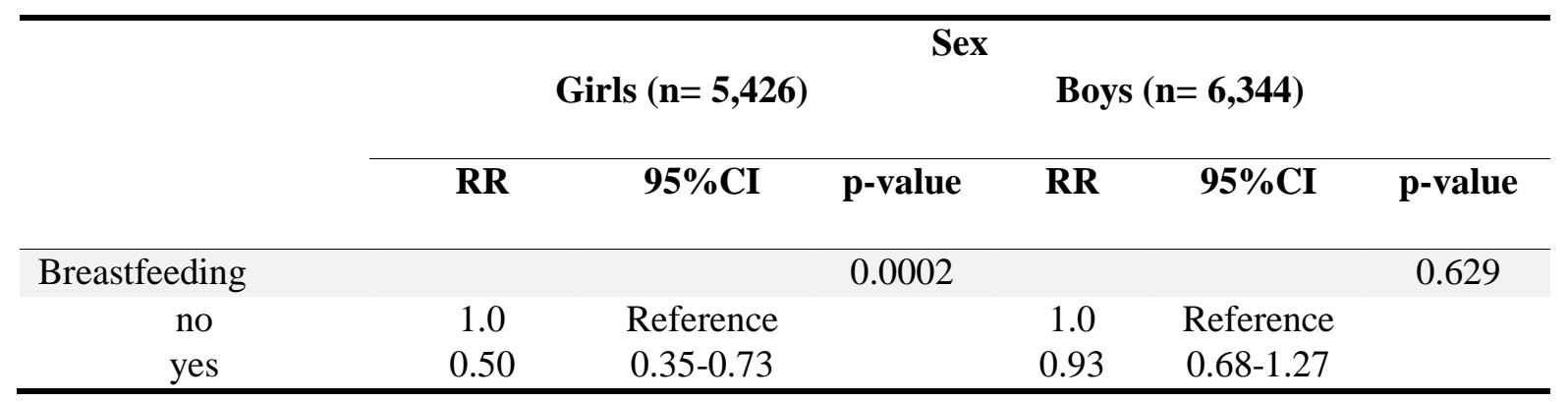

Abbreviations: $\mathrm{n}$, number of observations; $\mathrm{RR}$, relative risk; $\mathrm{CI}$, confidence interval.

${ }^{\text {a }}$ Estimates derived from generalized additive mixed-model with quasi-Poisson distribution adjusted for birth weight, gestational age, mode of delivery, maternal atopy, maternal education, maternal smoking during the pregnancy, older siblings, child care, weekly average of temperature, week of study (seasonal variation), week of age, distance to major roads and $\mathrm{PM}_{10}$. 
Table 8. Adjusted $^{\mathrm{a}}$ association of the postnatal parental smoking with overall respiratory

symptom score in infants without maternal smoking exposure during the pregnancy $(\mathrm{N}=402)$

(first 27 weeks of life)

\begin{tabular}{|c|c|c|c|c|c|c|c|}
\hline \multirow[b]{3}{*}{ Exposure } & \multirow{2}{*}{\multicolumn{2}{|c|}{$\begin{array}{c}\text { Complete data } \\
(\mathrm{n}=9,250)\end{array}$}} & \multicolumn{4}{|c|}{ Breastfed } & \multirow[b]{3}{*}{$\begin{array}{c}\mathbf{p -} \\
\text { value }^{\mathrm{b}}\end{array}$} \\
\hline & & & \multicolumn{2}{|c|}{ Yes $(n=8,127)$} & \multicolumn{2}{|c|}{ No $(n=1,123)$} & \\
\hline & $\begin{array}{c}\text { RR } \\
(95 \% \mathrm{CI})\end{array}$ & $\begin{array}{c}\text { p- } \\
\text { value }\end{array}$ & $\begin{array}{c}\text { RR } \\
(95 \% \mathrm{CI})\end{array}$ & $\begin{array}{c}\text { p- } \\
\text { value }\end{array}$ & $\begin{array}{c}\text { RR } \\
(95 \% \mathrm{CI})\end{array}$ & $\begin{array}{c}\text { p- } \\
\text { value }\end{array}$ & \\
\hline $\begin{array}{l}\text { Parental smoking in the first } \\
\text { year of life }\end{array}$ & & 0.014 & & 0.121 & & 0.115 & 0.206 \\
\hline no & Reference & & Reference & & Reference & & \\
\hline yes & $\begin{array}{c}1.35 \\
(1.106-1.71)\end{array}$ & & $\begin{array}{c}1.25 \\
(0.94-1.65)\end{array}$ & & $\begin{array}{c}1.72 \\
(0.88-3.37)\end{array}$ & & \\
\hline
\end{tabular}

Abbreviations: $\mathrm{N}$, number of individuals; $\mathrm{n}$, number of observations; $\mathrm{CI}$, confidence interval; RR, relative risk. ${ }^{a}$ adjusted for sex, birth weight, gestational age, maternal atopy, maternal education, older siblings, child care, breastfeeding, weekly average of temperature, week of study (seasonal component), week of age, distance to major roads, and $\mathrm{PM}_{10}$.

${ }^{\mathrm{b}} \mathrm{p}$-value for interaction. Interaction was tested by adding the product between the breastfeeding and corresponding exposure in the multivariable model. 
Figure 1

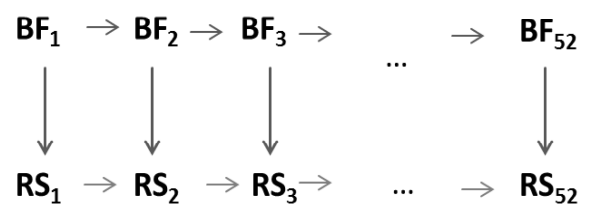


Figure 2

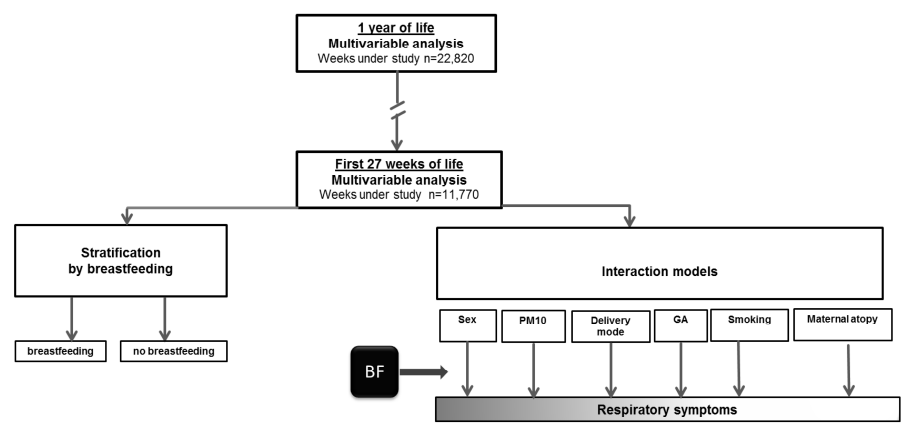


Figure 3

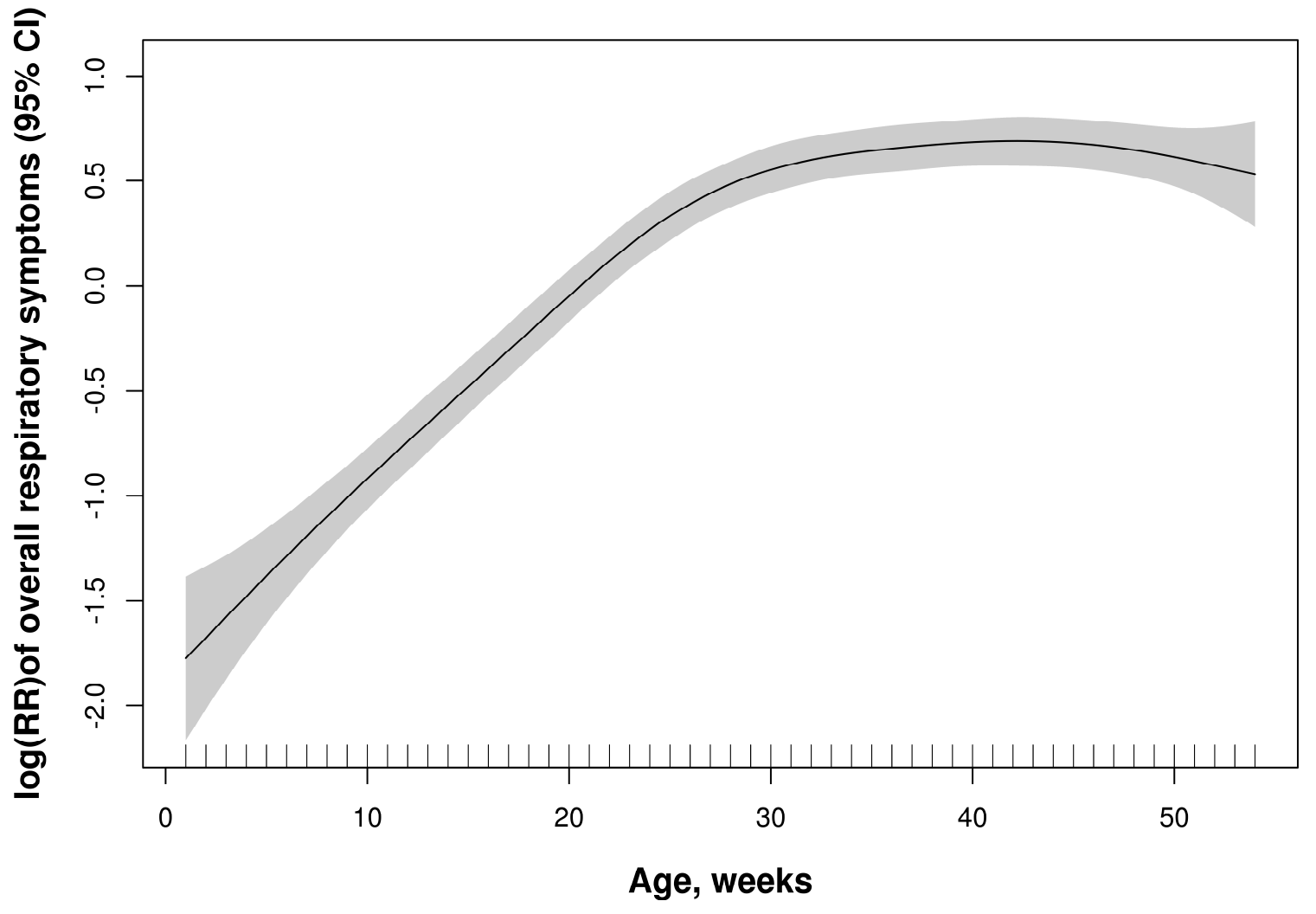

